CZASOPISMO INŻYNIERII LĄDOWEJ, ŚRODOWISKA I ARCHITEKTURY JOURNAL OF CIVIL ENGINEERING, ENVIRONMENT AND ARCHITECTURE

JCEEA, t. XXXIII, z. 63 (3/16), lipiec-wrzesień 2016, s. 381-390

\author{
Elżbieta RYBAK-WILUSZ ${ }^{1}$ \\ Paulina SAWICKA-CHUDY ${ }^{2}$ \\ Marian CHOLEWA ${ }^{3}$
}

\title{
ANALIZA WYKORZYSTANIA ENERGII SEONECZNEJ W BUDYNKU NA PODSTAWIE DANYCH EKSPLOATACYJNYCH
}

\begin{abstract}
Wielkość potencjału energetycznego określonego źródła energii, sposób wykorzystania energii oraz rodzaj zastosowanego rozwiązania technicznego są najczęściej rozpatrywane w ocenie efektywności i racjonalności wykorzystania energii odnawialnej. W opracowaniu przedstawiono analizę efektywności instalacji słonecznej pracującej dla potrzeb przygotowania ciepłej wody w budynku zamieszkania zbiorowego (dom studencki) w Rzeszowie.

Warunki nasłonecznienia zostały poddane analizie na podstawie informacji przyjętych z bazy danych klimatycznych stacji meteorologicznej Rzeszów-Jasionka. Posłużyły one do opracowano dla Rzeszowa sezonowego i rocznego napromieniowania płaszczyzny poziomej i odchylonej od niej pod różnymi kątami. W ramach opracowania przedstawiono charakterystykę analizowanego budynku oraz rozkład liczby mieszkańców i zużycie ciepłej wody użytkowej z lat 2009-2014. Na podstawie zapotrzebowania na ciepło obliczonego w oparciu o zużycie ciepłej wody na osobę, danych z pomiarów zużycia ciepłej wody oraz pomiarów dostarczonego ciepła sieciowego analizowano efektywność wykorzystania energii słonecznej po zamontowaniu kolektorów słonecznych. Relacje pomiędzy wartościami zapotrzebowania na ciepło wyznaczonego na podstawie zapotrzebowania na ciepło na osobę a zużyciem ciepła z pomiarów zostały poddane analizie.

Wykazano, że powierzchnia kolektorów powinna uwzględniać zapotrzebowanie na ciepło do ogrzania ciepłej wody, zwłaszcza w okresie wiosenno-letnim. Wyznaczony roczny (miesięczny) stopnień wykorzystania energii słonecznej do ogrzania ciepłej wody pozwolił wykazać, w jakim stopniu zastosowane kolektory słoneczne obniżają roczne zużycie ciepła dostarczanego z sieci cieplnej. Oceniono oszczędność ciepła w budynku zamieszkania zbiorowego uzyskaną po zamontowaniu kolektorów słonecznych oraz wskazano jakie czynniki wpływają na obliczenie optymalnej powierzchni kolektora słonecznego. Wnioski zawierają propozycje usprawnień, które mogą podwyższyć efektywność cieplną instalacji słonecznej i skrócić czas zwrotu poniesionych nakładów inwestycyjnych.
\end{abstract}

\footnotetext{
${ }^{1}$ Autor do korespondencji / corresponding author: Elżbieta Rybak-Wilusz, Politechnika Rzeszowska, Zakład Ciepłownictwa i Klimatyzacji, ul. Powstańców Warszawy 6, 35-959 Rzeszów; e-mail: elrywi@prz.edu.pl, tel. 178651445

${ }^{2}$ Paulina Sawicka-Chudy, Uniwersytet Rzeszowski, Katedra Biofizyki, Rzeszow, ul. Pigonia 1, 35-310 Rzeszów, e-mail: sawicka61@wp.pl

${ }^{3}$ Marian Cholewa, Uniwersytet Rzeszowski; mcholewa@ur.edu.pl, tel. 178518752
} 
Słowa kluczowe: efektywność energetyczna, napromieniowanie słoneczne, kolektory słoneczne, budynek zamieszkania zbiorowego

\section{Wprowadzenie}

Dzisiejszy świat stoi przed problemem zmian klimatycznych i stopniowego zużywania konwencjonalnych źródeł energii. $\mathrm{Z}$ tego powodu poprawa efektywności energetycznej, rozwój wykorzystania odnawialnych źródeł energii oraz ograniczenie oddziaływania energetyki na środowisko to główne kierunki przemian sektora energetycznego. Na świecie jak również w Polsce wzrasta wykorzystanie energii słonecznej. Pozyskanie energii słonecznej w Polsce w 2005 r. wynosiło 6,0 TJ, a już w roku 2014 r. wzrosło do 720 TJ. W porównaniu z 2010 (350 TJ) nastąpił ponad dwukrotny wzrost [1]. W okresie 2010-2014 udział energii słonecznej w krajowym pozyskaniu i wykorzystaniu energii ze źródeł odnawialnych wzrósł z $0,12 \%$ do $0,21 \%$ [2].

W ostatnich latach w Polsce wzrostowi wykorzystania odnawialnych źródeł energii towarzyszył intensywny postęp w badaniach nad kolektorami słonecznymi [3-5]. Dąży się do udoskonalenia technicznego tak, aby ich czas eksploatacji wynosił około 20 lat i były one cenowo opłacalne. Dlatego prowadzonych było wiele badań nad pracą instalacji solarnych [1] Głównym celem artykułu jest analiza efektywności cieplnej istniejącej instalacji kolektorów słonecznych zastosowanej do ogrzewania ciepłej wody użytkowej w budynku użyteczności publicznej, w którym ilość mieszkańców nie jest stała w ciągu roku. Wnioski z przeprowadzonej analizy będą pomocne dla projektantów i wykonawców zajmującymi się pozyskaniem energii ze Słońca.

\section{Potencjał energii słonecznej Rzeszowa}

Analizę napromieniowania dla Rzeszowa przeprowadzono na podstawie informacji zamieszczonych w bazie danych Ministra Infrastruktury i Rozwoju dla stacji meteorologicznej Rzeszów-Jasionka [6]. Warunki meteorologiczne w Rzeszowie (tak jak i w całej Polsce) charakteryzują się bardzo nierównym rozkładem promieniowania słonecznego w cyklu rocznym [7].

W oparciu o wzór (1) obliczono udział procentowy nasłonecznienia w półroczu letnim i zimowym dla różnych wartości nachylenia powierzchni kolektora w Rzeszowie. Wyniki obliczeń prezentuje tab. 1.

$$
p=\frac{H_{s}}{H_{y}} \cdot 100 \%,[\%]
$$

gdzie: $H_{s}$ - napromieniowanie (sezonowe, w półroczu zimowym lub letnim) $\left[\mathrm{kWh} / \mathrm{m}^{2} \cdot\right.$ sezon], $H_{y}$ - średnie roczne napromieniowanie $\left[\mathrm{kWh} / \mathrm{m}^{2} \cdot \mathrm{rok}\right]$. 
Roczne całkowite nasłonecznienie jednostkowej płaszczyzny horyzontalnej wynosi dla Rzeszowa $1051 \mathrm{kWh} / \mathrm{m}^{2}$. Zwiększenie kąta nachylenia kolektora do $45^{\circ}$ powoduje wzrost wartości energii o $101 \mathrm{kWh}\left(1152 \mathrm{kWh} / \mathrm{m}^{2}\right)$. Przy położeniu S45 kolektora $70 \%\left(806 \mathrm{kWh} / \mathrm{m}^{2}\right)$ całkowitej rocznej sumy nasłonecznienia przypada na sześć miesięcy sezonu wiosenno-letniego. W pozostałym okresie suma nasłonecznienia wynosi $30 \%\left(346 \mathrm{kWh} / \mathrm{m}^{2}\right)$. W półroczu zimowym najwięcej energii można otrzymać stawiając kolektor pod kątem $60^{\circ}$.

Tab. 1. Nasłonecznienie w półroczu letnim i zimowym dla Rzeszowa, kierunek S i N, na podstawie [6] Tab. 1. Irradiation in summer and winter semester in Rzeszow, at $\mathrm{S}$ and $\mathrm{N}$ direction, based on [6]

\begin{tabular}{|c|c|c|c|}
\hline Kierunek & $\mathbf{H}_{\mathbf{y}}\left[\mathbf{k W h} / \mathbf{m}^{2} \cdot \mathbf{r o k}\right]$ & Lato $(\mathbf{I V}-\mathbf{I X})$ & Zima (X-III) \\
\hline $\mathrm{S} 30^{\circ}$ & 1149 & $68 \%$ & $32 \%$ \\
\hline $\mathrm{S} 45^{\circ}$ & 1152 & $70 \%$ & $30 \%$ \\
\hline $\mathrm{S} 60^{\circ}$ & 1122 & $72 \%$ & $28 \%$ \\
\hline $\mathrm{N} 0^{\circ}$ & 1051 & $75 \%$ & $25 \%$ \\
\hline
\end{tabular}

Usytuowanie kolektorów słonecznych na pochylonym dachu zwiększa roczną efektywność systemu słonecznego. Średnioroczne miesięczne nasłonecznie dla kierunku $\mathrm{S}$ i kąta $45^{\circ}$ wynosi $96 \mathrm{kWh} /\left(\mathrm{m}^{2}\right.$ mies.), natomiast dla pozycji horyzontalnej jest około $10 \%$ niższe. Tylko w maju, czerwcu i lipcu uzyskuje się więcej energii, gdy kolektor ustawiony jest poziomo.

\section{Charakterystyka budynku}

\subsection{Liczba mieszkańców}

Analizowanym budynkiem zamieszkania zbiorowego jest 5-cio kondygnacyjny dom studencki „Promień” w Rzeszowie. W budynku na każdym piętrze znajduje się 26 trzy osobowych pokoi oraz pralnia i kuchnia. Na każdym piętrze znajdują się ogólnodostępne łazienki z prysznicami, w których zastosowano zawory czerpalne jednouchwytowe wyposażone w perlatory [8].

$\mathrm{Na}$ podstawie danych [8] z lat 2009-2014 można stwierdzić, że liczba mieszkańców od października do czerwca waha się od 263 do 324 osób. Natomiast w miesiącach letnich kiedy trwa przerwa wakacyjna (okres remontów i doraźnego pobytu studentów) liczba mieszkańców jest zdecydowanie niższa (tab. 2), (maksymalnie 120).

Tab. 2. Średnia miesięczna liczba mieszkańców w latach 2009-2014, na podstawie [8]

Tab. 2. The average monthly quantity inhabitants of in 2009-2014, based on [8]

\begin{tabular}{|c|c|c|c|c|c|c|}
\hline Rok/średnia liczba mieszańców & 2009 & 2010 & 2011 & 2012 & 2013 & 2014 \\
\hline okres X-VI (9 mies.) & 318 & 315 & 305 & 302 & 300 & 278 \\
\hline okres VII-IX (3 mies.) & 80 & 105 & 94 & 51 & 66 & 92 \\
\hline
\end{tabular}




\subsection{Zużycie ciepłej wody użytkowej}

Ze względu na charakter budynku i rodzaj odbiorców zużycie ciepłej wody użytkowej w akademiku utrzymuje się na wysokim poziomie. Analizowano zużycie ciepłej wody $\left(\mathrm{V}_{\mathrm{w}, \mathrm{z}}\right)$ w latach 2009-2014 uzyskane na podstawie wyników pomiarów [8] (rys. 1).

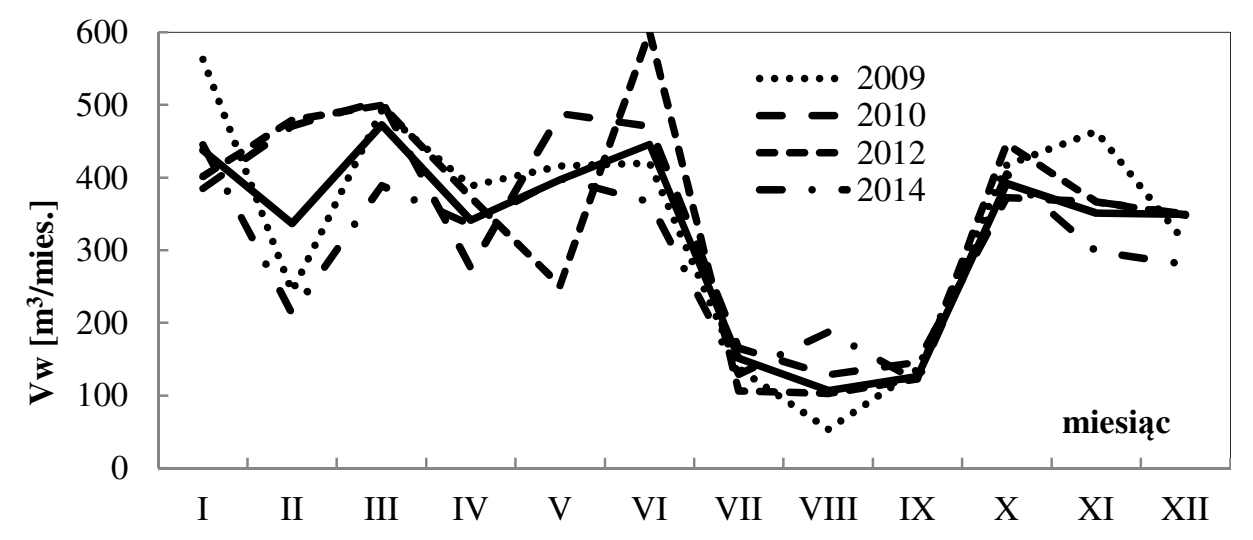

Rys. 1. Miesięczne zużycie ciepłej wody użytkowej w latach 2009-2014, na podstawie [8]

Fig. 1. Monthly hot water consumption in 2009-2014, own study based on [8]

Średnio roczne zużycie ciepłej wody wynosi około $3900 \mathrm{~m}^{3}$, przy czym od października do czerwca średnio miesięcznie $390 \mathrm{~m}^{3}$, (43 $\mathrm{dm}^{3} /($ dos. $\left.)\right)$. Natomiast w okresie wakacyjnym, średnio miesięcznie tylko $128 \mathrm{~m}^{3},\left(51 \mathrm{dm}^{3} /(\mathrm{d} \cdot o s)\right)$. Wynika to, ze wspomnianej już, małej liczby mieszkańców w okresie letnim. Na podstawie danych można wskazać, że w okresie maksymalnego nasłonecznienia zużycie ciepłej wody w budynku wynosi 40,1\% wartości rocznego zużycia.

\subsection{Potrzeby cieplne budynku}

Potrzeby cieplne domu studenta - ogrzewanie i przygotowaniem ciepłej wody zapewnia węzeł cieplny dwustopniowy. Węzeł c.w.u. był zasilany do 2009 roku tylko z miejskiej sieci cieplnej. Ciepła woda użytkowa podgrzewana była za pomocą 4 przepływowych wymienników typu Jad, a następnie magazynowana w dwóch zasobnikach o pojemności $1000 \mathrm{dm}^{3}$ każdy. Pomiar dostarczonego ciepła umożliwia ciepłomierz. System sterowania węzła c.w. nie został zintegrowany z systemem sterowania i regulacji instalacji słonecznej.

Zapotrzebowanie na ciepło do przygotowania ciepłej wody w budynku można wyznaczyć na podstawie liczby mieszkańców, w oparciu o pomiar zużytego ciepła oraz na podstawie rzeczywistego zużycia ciepłej wody. Obliczeniowe roczne zapotrzebowanie na energię końcową do przygotowania ciepłej wody z uwzględnieniem sprawności akumulacji $\left(Q_{W, N d}\right)$ wyznaczamy w oparciu o wzór [10]: 


$$
\begin{aligned}
& Q_{W, N d}=V_{C W i} \cdot L_{i} \cdot \rho_{W} \cdot c_{w} \cdot\left(\theta_{W}-\theta_{0}\right) \cdot k_{t} \cdot \frac{t_{U Z}}{3600 \cdot \eta},\left[\frac{\mathrm{kWh}}{\mathrm{rok}}\right] \\
& \operatorname{lub}\left[\frac{\mathrm{kWh}}{\mathrm{mies} .}\right]
\end{aligned}
$$

Przyjęto [8]: $V_{C W_{i}}=0,07 \mathrm{~m}^{3} /(\mathrm{os} \cdot \mathrm{d})$ jest to jednostkowe dobowe zapotrzebowanie na ciepłą wodę określone na podstawie dokumentacji projektowej; $c_{w}$-pojemność właściwa cieplna wody, $c_{w}=4,19 \mathrm{~kJ} /(\mathrm{kg} \cdot \mathrm{K}) ; \rho_{w}$ - gęstość wody, $\rho_{w} \approx 1000 \mathrm{~kg} / \mathrm{m}^{3} ; \theta_{W}=55^{\circ} \mathrm{C} ; \theta_{0}=10^{\circ} \mathrm{C} ; t_{U Z}=365 \mathrm{~d} / \mathrm{rok}, t_{U Z}=31(30) \mathrm{d} / \mathrm{mies}$; $k_{t}$ - mnożnik korekcyjny dla temperatury innej niż $55^{\circ} \mathrm{C}, k_{t}=1 ; L_{i}-$ liczba osób.

Roczne zapotrzebowanie na energię końcową $\left(Q_{W, z}\right)$ do przygotowania c.w.u. uwzględniające sprawność akumulacji na podstawie rzeczywistego zużycia c.w.u. wyznaczamy z zależności [10]:

$$
Q_{W, z}=V_{w, z} \cdot \rho_{W} \cdot c_{w} \cdot \frac{\left(\theta_{W}-\theta_{0}\right)}{3600 \cdot \eta},\left[\frac{\mathrm{kWh}}{\mathrm{rok}}\right] \operatorname{lub}\left[\frac{\mathrm{kWh}}{\mathrm{mies} .}\right]
$$

gdzie: $V_{w, z}\left[\mathrm{~m}^{3} / \mathrm{rok}\right]$ jest to rzeczywiste zużycie c.w. (dane z pomiarów) [8].

Na podstawie zależności (2) i (3) zostały wyznaczone miesięczne zapotrzebowania na energię $Q_{W, N d} ; Q_{W, z}$. Sprawność akumulacji w elementach pojemnościowych systemu ciepłej wody przyjęto na podstawie [10], $\eta=0,86$. Sprawności wytwarzanie i przesyłu ciepła z uwagi na lokalny charakter produkcji ciepła i niskie oszacowane straty przesyłu przyjęto równą $1,0 . Q_{W, z}$ jest obliczane na podstawie pomierzonego zużycie ciepłej wody, natomiast $Q_{W, N d}$ obliczono uwzględniając liczbę osób oraz teoretyczne średnie dobowe zapotrzebowanie na ciepłą wodę na osobę. Zużycie ciepła w ciągu roku (miesiąca) $\left(Q_{W, p}\right)$ są danymi otrzymanymi z pomiarów [8]. W okresie pracy instalacji ciepłej wody bez kolektorów słonecznych przyjęto założenie:

$$
Q_{W, p} \approx Q_{W, z,} \approx Q_{W, N d},[\mathrm{kWh} / \mathrm{rok}] \text { lub }[\mathrm{kWh} / \text { mies. }]
$$

\subsection{Energia dostarczona ze Słońca}

W celu zmniejszenia kosztów wytworzenia ciepła w domu studenckim zamontowano jesienią 2009 r. cztery zespoły baterii płaskich kolektorów słonecznych (po 5 kolektorów w każdym) o powierzchni $36 \mathrm{~m}^{2}$. Wspomagają one instalację centralnej ciepłej wody użytkowej zasilaną z istniejącego węzła cieplnego, podłączonego do miejskiej sieci ciepłowniczej.

Energia cieplna z kolektorów słonecznych dostarczana jest do trzech pojemnościowych podgrzewaczy ciepłej wody o pojemności $750 \mathrm{dm}^{3}$ każdy, włączonych szeregowo w system podgrzewu ciepłej wody z sieci miejskiej. Ogrzana $\mathrm{w}$ podgrzewaczach pojemnościowych woda przepływa przez wymienniki węzła c.w., w których w okresach obniżonego nasłonecznienia dogrzewana jest 
do docelowej temperatury lub dostarczana bez podgrzewu do zasobników buforowych. W celu schłodzenia cieczy grzewczej kolektorów, gdy temperatura glikolu wzrośnie powyżej $110^{\circ} \mathrm{C}$ zastosowano chłodnicę glikolu [9]. Instalacja słoneczna nie została wyposażona w licznik ciepła. W celu wyznaczenia energii dostarczonej ze Słońca $E_{k o l}$ skorzystano ze wzoru:

$$
E_{k o l}=H_{M} \cdot A_{k o l} \cdot \eta_{k}\left[\frac{\mathrm{kWh}}{\mathrm{mies} .}\right] \operatorname{lub}\left[\frac{\mathrm{kWh}}{\mathrm{rok}}\right]
$$

Przyjęto: $H_{M}[6], A_{k o l}=36 \mathrm{~m}^{2}$ [8], założono $\eta_{k}=0,81[1]$.

Stopień pokrycia zapotrzebowania na ciepło przez kolektory słoneczne $(\lambda)$ obliczono ze wzorów:

$$
\begin{aligned}
& \lambda=E_{k o l} \cdot \frac{100}{Q_{W, N d}} \\
& \lambda=E_{k o l} \cdot \frac{100}{Q_{W, z}} \\
& \lambda=E_{k o l} \cdot \frac{100}{Q_{W, p}}
\end{aligned}
$$

W okresie pracy kolektorów słonecznych przyjęto następujące założenie:

$$
Q_{W, z}=Q_{W, p}+E_{\text {kol ex }},[\mathrm{kWh} / \mathrm{rok}],[\mathrm{kWh} / \text { mies.] }
$$

gdzie $\mathrm{E}_{\mathrm{kol} \mathrm{ex}}$ jest to eksploatacyjny zysk energii słonecznej z kolektora.

\section{Wyniki}

Do 2009 r. ciepło do budynku dostarczane było tylko z miejskiej sieci cieplnej, natomiast w 2010 r. zastosowano kolektory słoneczne [11].

Wyniki obliczeń miesięcznego zapotrzebowania na energię końcową w 2009 r. $Q_{W, N d}(2), Q_{W, z}(3), E_{k o l}(5)$ oraz zużycia energii cieplnej na podstawie pomiarów $Q_{W, p}[8]$ przedstawiono na rys. 2.

Dla przyjętego stałego nachylenia kolektorów $45^{\circ}$, kierunek $\mathrm{S}$ energia dostarczona ze Słońca $E_{k o l}$ w ciągu roku wynosi $33580 \mathrm{kWh}$, w okresie wiosennoletnim $23500 \mathrm{kWh}$, a zimą $10080 \mathrm{kWh}$. Obliczenia wykazały, że roczne wartości $Q_{W, N d}$ w latach 2009-2014 są o ok. $49 \%$ - 70\% większe od $Q_{W, z}$. 


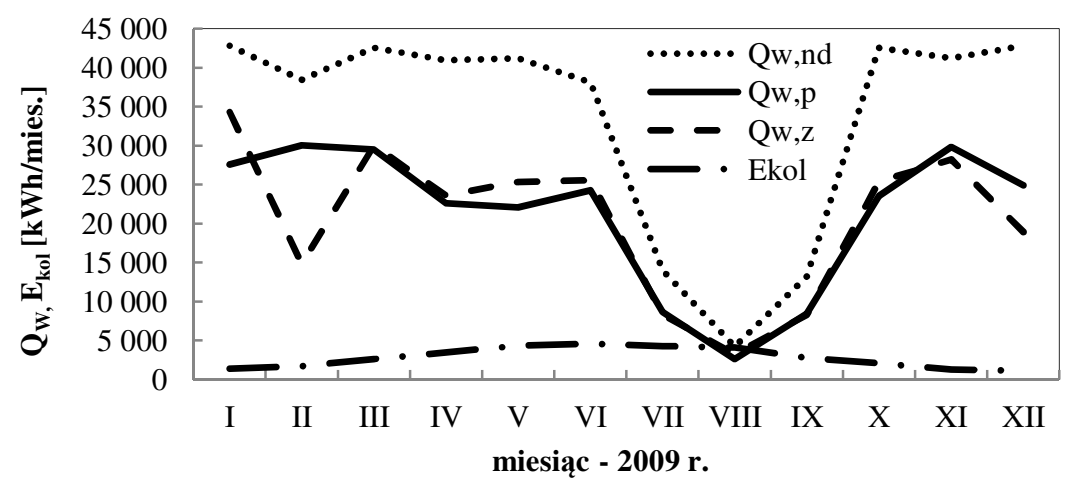

Rys. 2. Miesięczne wartości $Q_{W, N d ;} Q_{W, z ;} Q_{W, p}$ oraz $E_{k o l}$ w roku 2009

Fig. 2. Summary of monthly values of $Q_{W, N d} ; Q_{W, z} ; Q_{W, p}$ and $E_{k o l}$ in 2009

Średni miesięczny stopień pokrycia zapotrzebowania na ciepło przez kolektory słoneczne obliczony w oparciu o wzór (6) w 2009 r. wynosił dla okresu letniego $29,8 \%$, w okresie zimy $4,0 \%$, a średnioroczny $16,7 \%$. Natomiast wyznaczony na podstawie pomiarów zużycia ciepła $Q_{W, p}$ (wzór 8) w 2009 wyniósł odpowiednio: $39,3 \%$ (lato); $6,1 \%$ (zima) i $22,7 \%$ (średnioroczny). Wynika to z większych wartości obliczeniowego zapotrzebowania na ciepło $Q_{W, N d}$ w stosunku do wartości pomierzonych $Q_{W, p}$ (rys. 2).

Na podstawie obliczeń, (wzór $(7),\left(Q_{W, z}\right)$ ), przyjęta powierzchnia kolektorów powinna zapewnić od 13,6\% (2009 r.) do 15,5\% (2014 r.) rocznych potrzeb cieplnych (rys. 3). W okresie wiosenno-letnim od 23,1\% (2009) do 25,1\% (2014).

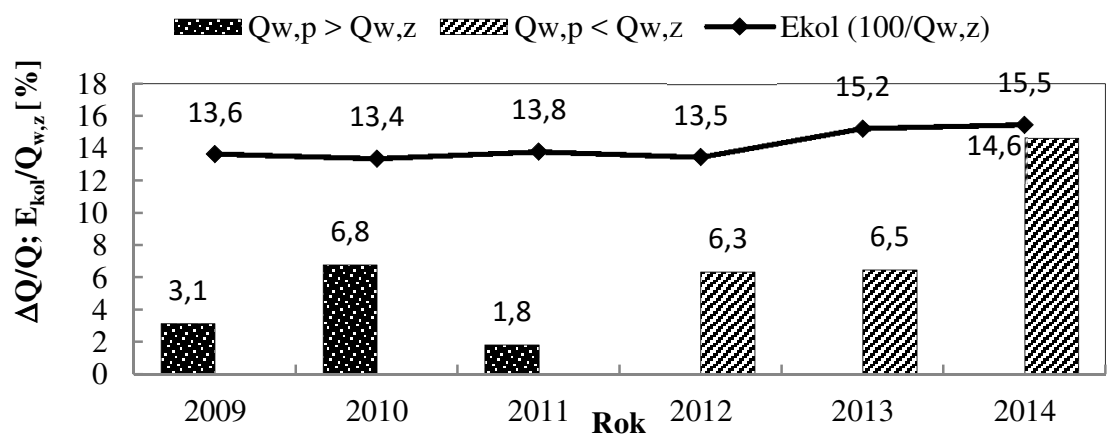

Rys. 3. Procentowa różnica pomiędzy QW, p ; QW, z i $\lambda$ w latach 2009-2014

Fig. 3. Percentage difference between QW, p ; QW, z and $\lambda$ from 2009 to 2014 
Przeprowadzona analiza ekonomiczna opłacalności wykorzystania kolektorów słonecznych wykazała, że prosty czas zwrotu kosztów modernizacji (SPBT) obliczony jako stosunek kosztów inwestycyjnych do oszczędności wyniesie oko-

ło 16 lat [9]. Należy zaznaczyć, że w 2010 r. wykonano instalacją kolektorową. Rzeczywiste pomierzone zużycie ciepła w latach 2011-2014 $\left(Q_{W, p}\right)$ jest energią dostarczoną z miejskiej sieci cieplnej. W latach 2010-2014 do ogrzewania wody wykorzystywano energię promieniowania słonecznego oraz ciepło z miejskiej sieci cieplnej. Wyniki rocznego zużycia ciepła $Q_{W, p}$ (pomiar), $Q_{W, z}(2)$ oraz $E_{k o l}$ (4) w latach 2010-2014 przedstawia rys. 4.

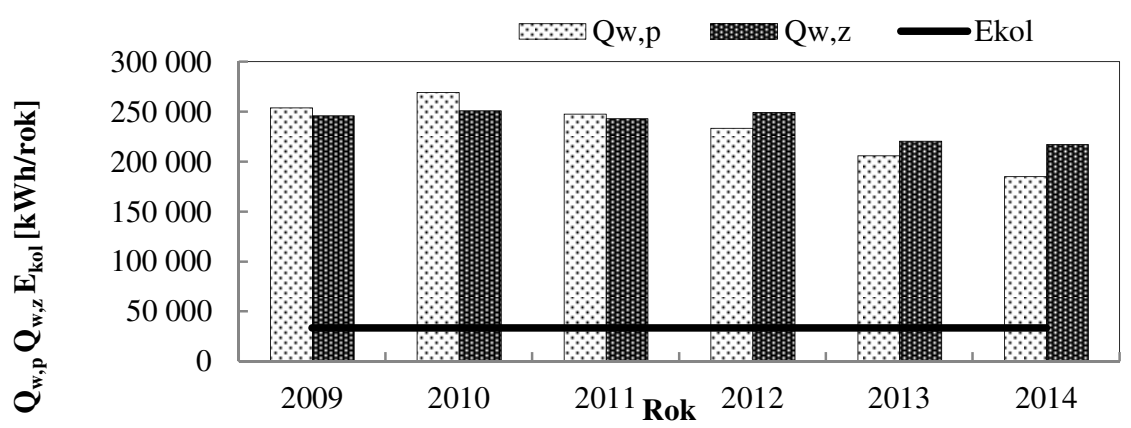

Rys. 4. Zestawienie porównawcze QW, p; QW, z oraz Ekol w 2009 r. i latach 2010-2014

Fig. 4. Comparison of QW, p, QW, z and Ekol in 2009 and in from 2010 to 2014

\section{Analiza i wnioski}

Analizując zebrany materiał badawczy można zauważyć, że:

- Wartości zapotrzebowania na ciepło obliczone na podstawie obliczeniowego zapotrzebowania na energię na osobę $Q_{W, N d}$ (na podstawie przepisów) są od $49 \%$ do $70 \%$ większe od rzeczywistego zużycia ciepła (z pomiarów).

- Kolektory słoneczne do ogrzewania ciepłej wody należy stosować w budynkach o dużym i stałym w okresie wysokiego nasłonecznienia (od kwietnia do września) zużyciu ciepłej wody. W analizowanym budynku $36 \mathrm{~m}^{2}$ powierzchni kolektorów może dostarczyć średnio w okresie lata tylko do $25 \%$ ciepła do ogrzewania ciepłej wody (średnio w roku 15,5\%), (wzór (6) rys. 3, 4). Nie przynosi to dużych oszczędność ciepła natomiast wydłuża czas zwrotu poniesionych nakładów inwestycyjnych.

- Celem obliczeń było wykazanie oszczędności ciepła przy zastosowaniu instalacji kolektorowej. W roku 2010 nastąpił montaż instalacji, rok 2011 to uruchomienie instalacji - okres przejściowy. Kolejne lata ukazują zmniejszenie zużycia ciepła sieciowego. Spowodowane jest to przede wszystkim pracą instalacji słonecznej oraz zmniejszającą się liczba użytkowników. Od 2012 r. zużycie 
ciepła sieciowego $Q_{W, p}$ maleje, w stosunku do zapotrzebowania na energię cieplną do przygotowania ciepłej wody $Q_{W, z}$. W analizowanej instalacji wykazano, że zastosowane kolektory słoneczne obniżają roczne zużycia ciepła dostarczanego z sieci cieplnej od $6,3 \%$ do $14,6 \%$ (rys.3). Niska efektywność cieplna jest spowodowana małą powierzchnią kolektorów, nie dostosowaną do wysokiego zużycia ciepła do ogrzewania ciepłej wody w domu studenckim.

Wnioski ogólne.

- W systemach zasilanych z sieci ciepłowniczej dobór oraz ocenę efektywności kolektorów słonecznych należy wykonać na podstawie zużycia ciepła otrzymanego z pomiaru (metoda zużyciowa).

- Instalacje słoneczne powinny być wyposażone w liczniki ciepła zwłaszcza w budynkach o dużym zużyciu ciepła solarnego (budynki użyteczności publicznej). Pozwoli to na ocenę pracy i efektywności instalacji słonecznej w warunkach eksploatacyjnych.

- Powierzchnia absorbera zamontowanych kolektorów powinna wynikać z zużycie ciepła w okresie maksymalnego nasłonecznienia (okres letni). W tym okresie zużycie ciepła do ogrzewania ciepłej wody powinno być największe. Wówczas to duża oszczędność ciepła z powodu wysokiego współczynnika wykorzystania energii słonecznej obniży czas zwrotu poniesionych nakładów inwestycyjnych.

- W celu ograniczenia wydatków wynikających z dużego rozbioru wody, proponuje się:

- zwiększenie powierzchni kolektorów słonecznych (co najmniej dwukrotnie) uwzględniając możliwość lokalizacji bez ingerencji w układ akumulacji ciepła,

- zwiększenie liczby odbiorców w okresie letnim (akademicka baza hotelowa),

- dostosowanie systemu sterowania i regulacji instalacji słonecznej do systemu sterowania węzła cieplnego.

Wykonana analiza obrazuje przykład instalacji słonecznej, w której oczekiwane efekty związane z wykorzystaniem energii słonecznej nie przekładają się na korzyści eksploatacyjne.

\section{Literatura}

[1] Główny Urząd Statystyczny. Portal Informacyjny. http://stat.gov.pl, dostęp 14.10.2015.

[2] Eurostat. http://ec.europa.eu/eurostat, dostęp 14.10.2015.

[3] Z. Pluta "Evacuated tubular or classical flat plate solar collectors?," Journal of Power Technologies 91 (3) (2011) 158-164.

[4] E. Zambolin, D. D. Col, "Experimental analysis of thermal performance of flat plate and evacuated tube solar collectors in stationary standard and daily conditions, Solar Energy 84 (8) (2010) 1383-1396. 
[5] R. Tang, W. Gao, Y. Yu, H. Chen, Optimal tilt-angles of all-glass evacuated tube solar collectors, Energy 34 (2009) 1387-1395.

[6] Ministerstwo Infrastruktury i Budownictwa, http://www.mib.gov.pl, dostęp 20.08.2015.

[7] Chwieduk Dorota, "Solar Energy in Buildings. Thermal Balance for Efficient Heating and Cooling", 1st Edition, Elsevier Science \& Technology Books, 2014.

[8] Dział Utrzymania Ruchu, Politechnika Rzeszowska, http://www.prz.edu.pl, dostęp 28.08.2015

[9] P. Sawicka, E. Rybak-Wilusz, V. Pisarev, "Analiza systemu zaopatrzenia w wodę ciepłą w akademiku Promień Politechniki Rzeszowskiej", Prace Kół Naukowych Politechniki Rzeszowskiej 2009/2010, 293-301, (2011) ISBN 978-83-7199-656-6.

[10]Rozporządzenia Ministra Infrastruktury z dnia 6.11.2008 r. w sprawie metodologii obliczania charakterystyki energetycznej budynku (Dz.U. Nr 201/2008 poz. 1240).

[11] http://www.prolandsklep.co/pl/p/HEWALEX-KS-2000SP/276, dostęp 28.08.2015.

\section{ANALYSIS THE SOLAR ENERGY UTILIZATION IN THE BUILDING BASED ON OPERATING DATA}

\section{S u m m a r y}

In the assessment of the efficiency and rational use of renewable energy taken into account they are the size of the energy potential of a particular source of energy, the use of energy and kind of the technical solution. This paper presents an analysis of a solar thermal system which is working to produce hot water in a collective residence building in Rzeszow. Irradiance exposure were analyzed based on information obtained from database available online for the meteorological station in Rzeszow-Jasionka.

The following part presents the characteristic of the analyzed building and the distribution of population and consumption of hot water from the years 2009-2014. The heat demand was calculation based on hot water consumption per person per day, dataset from measurements of consumption of hot water and also the measurement of heat consumption. The efficiency of solar energy conversion after installing solar thermal collectors had analyzed. The paper presents also way of calculation annually (monthly) ratio of utilization of solar energy to heat water. It was calculating reducing of heat demand from heat distribution network after installing the solar thermal collectors.

It presented elements that may impact on the calculation optimal area of solar thermal collectors. The improvements which are proposed may to increase the efficiency of solar thermal installation. It was experimentally proved that area of solar thermal collectors should take into account hot water demand of the building in summer season. It causes that the investments payback cost time is shortened.

Keywords: thermal efficiency, irradiation, solar thermal collectors, collective residence building

DOI: $10.7862 / \mathrm{rb} .2016 .221$

Przestano do redakcji: 20.05.2016 $r$.

Przyjęto do druku: $30.11 .2016 \mathrm{r}$. 